1995119509

$5,8.72$

N95-25929 44642

APPENDIX $Q$

Experimental and Calculated LET Distributions in the Cosmos-2044 Biosatelifte Orbit

by

V.E. Dudkin, O.N. Karpov, Yu.V. Potapov, A.B. Akopova, N.V. Magradze, A.A. Moiseenko, E.V. Benton, A.L. Frank and $J \cdot N$. Natts, Jr.

(196) 


\title{
EXPERIMENTAL AND CALCULATED LET DISTRIBUTIONS IN THE COSMOS-2044 BIOSATELLITE ORBIT
}

\author{
V. E. DUdRun, " O. N. Karpov," YU. V. Potapov," A. B. AKopova, † N. V. Magradze, † A. A. Motsmenko, $\dagger$

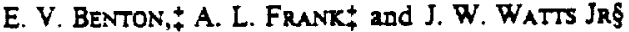 \\ - Research Center of Space Craft Radiation Safety, Ministry of Public Health, Moscow 123182, U.S.S.R. \\ +Yerevan Institute of Physics, Yerevan, U.S.S.R.; +University of San Francisco, San Francisco, CA 94117 , \\ U.S.A. and §NASA Marshall Spaceflight Center, Huntsville, AL 35812, U.S.A.
}

(Received 21 February 1991; in revised form 7 May 1991)

\begin{abstract}
During the flight of the Cosmos-2044 biosatellite, joint U.S.S.R.-U.S.A. investigations of different characteristics of cosmic radiation (CR) in the near-Earh environment were carried out. The U.S. dielectric track detectors CR-39 and Soviet BYa-and BR-type nuclear photo-emulsions were used as detectors. The present work shows some results of experimental measurements of linear energy transfer (LET) spectra of CR particles obtained with the use of these detectors, which were placed both inside and outside the sateilite. The LET spectra measurement with plastic detectors is composed of rwo parts: the measurement of galactic cosmic rays (GCR) particles, and of short-range particles. The contributions of these components to the total LET distribution at various thicknesses of the shielding were analyzed and the results of these studies are presented. Calculated LET spectra in the Cosmos-2044 orbit were compared with experimental data. On the basis of experimental and calculated values of the LET spectra, absorbed and equivalent $C R$ doses were calculated. In the shielding range of $1-1.5 \mathrm{~g} \mathrm{~cm}^{-2}$, outside the spacecraft, the photo-emulsions yielded $10.3 \mathrm{mrad} \mathrm{d}^{-1}$ and $27.5 \mathrm{mrem} \mathrm{d}^{-1}$ (LET $\geq 2 \mathrm{MeV} \mathrm{cm}^{-1}$ ) while the CR.39 yielded averages of $1.43 \mathrm{mrad} \mathrm{d} \mathrm{d}^{-1}$ and $13.4 \mathrm{mrem} \mathrm{d^{-1 }}$ (LET $\geq 40 \mathrm{MeV} \mathrm{cm} \mathrm{cm}^{-1}$ ). Inside the

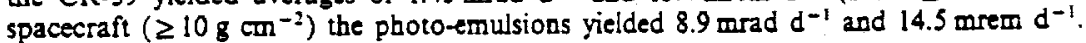

\section{INTRODUCTION}

THE EXPERIMENTAL studies which were begun on board Cosmos-1887 (Akopova et al., 1990) showed the necessity of extending investigations of the nearEarth space environment using passive detectors. The present experiments had two characteristic properies: the orbit of Cosmos-2044 was near to polar (inclination $i \simeq 82^{\circ}$ ), and the light period almost coincided with the maximum of solar activity (SA).

In our previous work (Akopova et al., 1990) we analyzed the experimental LET distributions which were available at that time and showed some orbital dependence. It was noted that some orbits were not amply studied. Also, it was necessary to verify the conclusion that absolute values of LET distributions, and, consequently, absorbed and equivalent doses, are more strongly dependent on orbit inclination ( $i$ ) than on altitude, for $H=200-400 \mathrm{~km}$ above the Earth, in the case of highly inclined ( $i \geq 60^{\circ}$ ) orbits.

As is apparent from the above, the main purpose of the present investigation was to obtain experimental data about IET distributions of the CR particles in a nearly polar orbit of the satellite in close to maximum SA-phase, using various passive detectors. Comparisons of experimental data for LET distributions at different shielding thicknesses are also discussed.

\section{EXPERIMENTAL TECHNIQUE}

The flight parameters of the satellite were as follows: inclination $(i) \simeq 82^{\circ}$, apogee altitude $=294 \mathrm{~km}$, perigee $=216 \mathrm{~km}$, duration $=14$ days from 15 to 29 September 1989 ; i.e. the flight was in the period close to the solar maximum.

The assemblies of passive detectors (plastic detectors CR-39 and BYa and BR-type nuclear photoemulsions) were placed on the lid and the bottom of a special container with scientific equipment (outside assemblies), and inside the satellite (nuclear photoemuisions).

After exposure and recovery, the layers of nuclear emulsions were treated by the selective-development technique (Akopova et al., 1983) to ensure quenching of the accompanying background and threshold sensitivity control in a broad interval of LET. It is then possible to develop only those particle tracks for which the LET is not below threshold. 
In the experiment. BYa-type photo-emulsions were used to measure LET spectra within an interval from 12 to $3.5 \times 10^{3} \mathrm{MeV} \mathrm{cm}^{-:}$in biological tissue with the lower limit being defined by the effective sensitivity of BYa-type emulsions. In several cases in this experiment we have succeeded in obraining the planar fluence of the particles with LET $\simeq 2.0 \mathrm{MeV} \mathrm{cm}-1$ in tissue, using the relativistic BR-type emulsion, thereby making it possible to evaluate the doses from CR particles practically within the whole LET interval.

The CR-39 detectors have higher effective LET thresholds of track detection $\left(\sim 40 \mathrm{MeV} \mathrm{cm} \mathrm{cm}^{-1}\right.$ in tissue). In the present experiment, their assemblies were located, as a rule, next to nuclear emulsions to provide more accurate comparison of measurements made with the two types of detectors, with due account taken of the difference in LET intervals of the particles which are registered by these detectors.

Two integral LET spectra were measured in each location of the CR-39-the spectrum generated by the GCR particles which are not stopped in the detector, and the spectrum formed by short-range particles. Since the CR-39 registers particles with LET $\geq 40 \mathrm{MeV} \mathrm{cm}^{-1}$ in tissue (corresponding to the protons with energy less than $\sim 12 \mathrm{MeV}$, alpha particles with energy less than $\sim 65 \mathrm{MeV}^{\text {nucleon }}{ }^{-1}$, and particles heavier than carbon with any energy) and the satellite had an almost polar orbit, a great number of low-energy particles were stopped and registered in the detectors.

Besides the above-mentioned detectors, other investigators measured the IET spectra on board Cosmos-2044 using plastic track detectors (Beaujean et al., 1990) and detectors based on AgCl (Baican e: al., 1990).

In this work. together with experimental studies. LET spectra for the Cosmos-2044 orbit were calculated according to two different programs developed in the U.S.S.R. and the U.S.A. The U.S. program takes into consideration the contribution to the total LET distribution of the GCR particles (protons and alpha particles only), protons of the intemal radiation belt of the Earth, and the contribution from the anomalous component with the charge $Z=1$. The program takes into account the close-to-maximum SA phase during which the flight took place, geomagnetic cut-off. and screening of particles by the Earth. However, it disregards geomagnetic disturbances. A similar program was developed in the U.S.S.R., but it included only the contribution of GCR particles from hydrogen to nickel.

To compare experimental data with calculations. LET distributions from the GCR particles with $Z>3$ were calculated following the L.S.S.R. code, and added to the corresponding LET distributions resulting from the $L^{*} . S$. program. All experimental and calculated LET distributions were normalized for $2 \pi$ geometry:
Table 1. Fluxes of CR paricles with LET $>40 \mathrm{MeV} \mathrm{cm}^{-1}$ in tissue behind small shieldings $\left(\delta<2.0 \mathrm{~g} \mathrm{~cm}^{-2}\right)$ on board the biosatellite Cosmos-2044

\begin{tabular}{lccc}
\hline \multicolumn{3}{c}{$\begin{array}{c}\text { Particles } \\
\mathrm{cm}^{2} \text { s sr } \times 10^{-4}\end{array}$} & \multicolumn{1}{c}{$\delta$} \\
\cline { 1 - 3 }$N_{\mathrm{ST}}$ & $N_{\mathrm{GCR}}$ & $N_{\mathrm{L}}$ & $\mathrm{g} \mathrm{cm}^{-2}$ \\
\hline 10.23 & 5.60 & 15.83 & 0.0935 \\
25.18 & 2.11 & 27.29 & 0.164 \\
12.83 & 2.02 & 14.85 & 0.239 \\
10.92 & 1.82 & 12.74 & 0.250 \\
5.58 & 1.72 & 7.30 & 0.397 \\
2.27 & 2.20 & 4.47 & 1.49 \\
1.53 & 1.52 & 3.05 & 1.95 \\
\hline
\end{tabular}

$N_{\tau}=$ tocal flux: $N_{\text {OCR }}=$ flux of GCR particles; $N_{S T}=$ flux of particles producing short-length tracks.

\section{RESULTS AND DISCUSSION}

Experimental data concerning the integral LET distributions on the external surface of Cosmos-2044 were obtained with two assemblies of detectors: the U.S. detectors F-I and F-2, behind shielding thicknesses $\delta=0.164,0.239,0.397,1.47$ and $1.95 \mathrm{~g} \mathrm{~cm}^{-2}$ (assembly F-1) and $\delta=0.0935,0.250,1.49$ and $1.97 \mathrm{~g}$ $\mathrm{cm}^{-2}$ (assembly $\mathrm{F}-2$ ), and the Soviet detectors, $\delta=1.2$ and $1.9 \mathrm{~g} \mathrm{~cm}^{-2}$. Inside the satellite, LET spectra were measured with the Soviet detectors.

Since the orbit of the satellite was near to polar, it was assumed that the number of low-energy particles with various charges was great and this would cause a difference in fluxes of particles registered on the external surface of the satellite even behind shieldings slightly differing in thickness. This premise can be confirmed by the data in Table 1 which exhibit the values of fiuxes of particles measured with the U.S. detectors behind small shielding with $\delta<2 \mathrm{~g} \mathrm{~cm}^{-2}$ at LET $>40 \mathrm{MeV} \mathrm{cm} \mathrm{cm}^{-1}$ in tissue on board Cosmos 2044. Shielding with thickness under $1.5 \mathrm{~g} \mathrm{~cm}^{-2}$ is made of plastic; at $\delta>1.5 \mathrm{~g} \mathrm{~cm}^{-2}$ shielding is composed of $0.59 \mathrm{~g} \mathrm{~cm}^{-2}$ stainless steel, $0.120 \mathrm{~g} \mathrm{~cm}^{-2}$ is

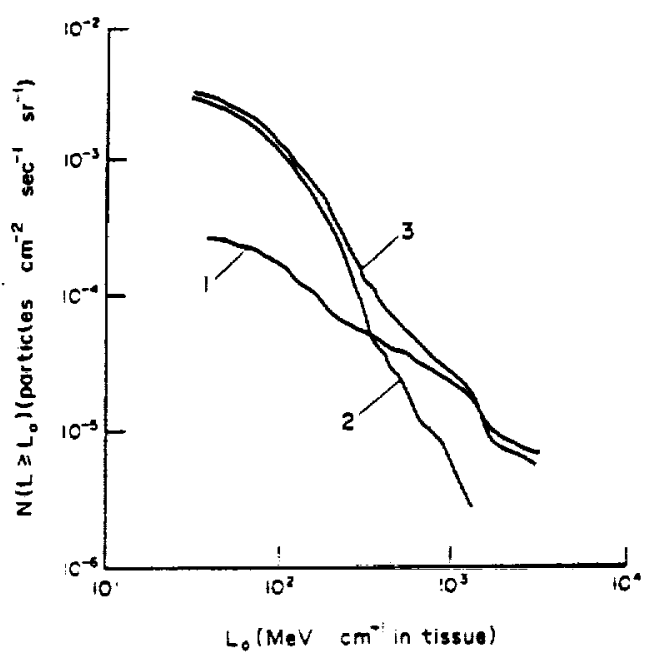

FIG 1. Integral LET spectrum measured on board Cosmos2044 with CR-39 track detectors behind $\delta=0.164 \mathrm{~g} \mathrm{~cm}^{-2}$. 


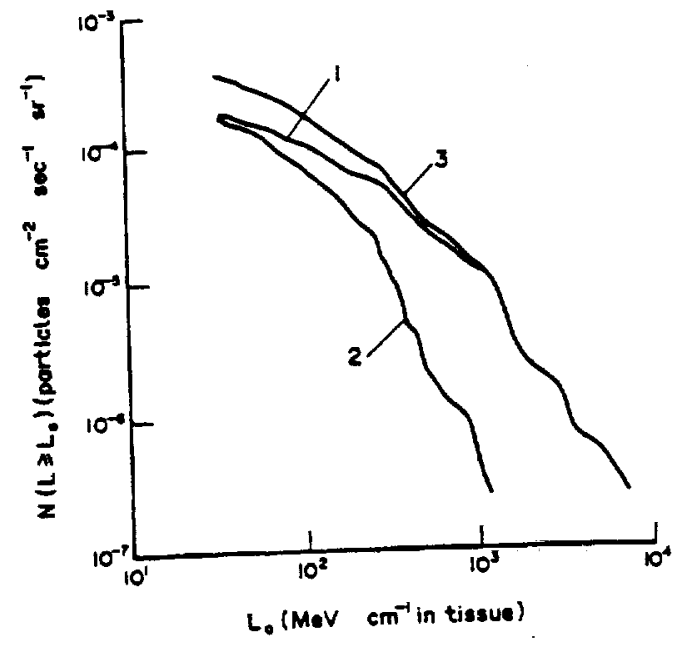

FiG. 2. Integral LET spectrum measured on board Cosmos2044 with CR-39 track detectors behind $\delta=1.95 \mathrm{~g} \mathrm{~cm} \mathrm{~cm}^{-2}$.

nuclear emulsion and the rest is plastic. Flux values corresponding to the smallest thicknesses in the F-1 and $F-2$ containers $\left(0.164\right.$ and $\left.0.0935 \mathrm{~g} \mathrm{~cm}^{-2}\right)$ show that there was a significant difference in orientation or external shielding between the two.

Moreover, this bypothesis is clearly verified by the data presented in Figs 1 and 2. Figure 1 shows LET distributions measured with CR-39 on the external surface of the satellite behind shielding with $\delta=0.164 \mathrm{~g} \mathrm{~cm}^{-2}$; Fig. 2 shows the analogous distributions at $\delta=1.95 \mathrm{~g} \mathrm{~cm}^{-2}$. In these figures, curves 1 denote LET spectra formed by the GCR particles; curves 2, the LET spectra of low-energy, short-range particies; and curves 3, their total. Comparing the curves from Figs 1 and 2 and analyzing similar LET distributions measured in this experiment behind other shieldings and at $L_{0}>40 \mathrm{MeV} \mathrm{cm}^{-1}$, it becomes evident that at $\delta<1.0 \mathrm{~g} \mathrm{~cm}^{-2}$ the main contributors

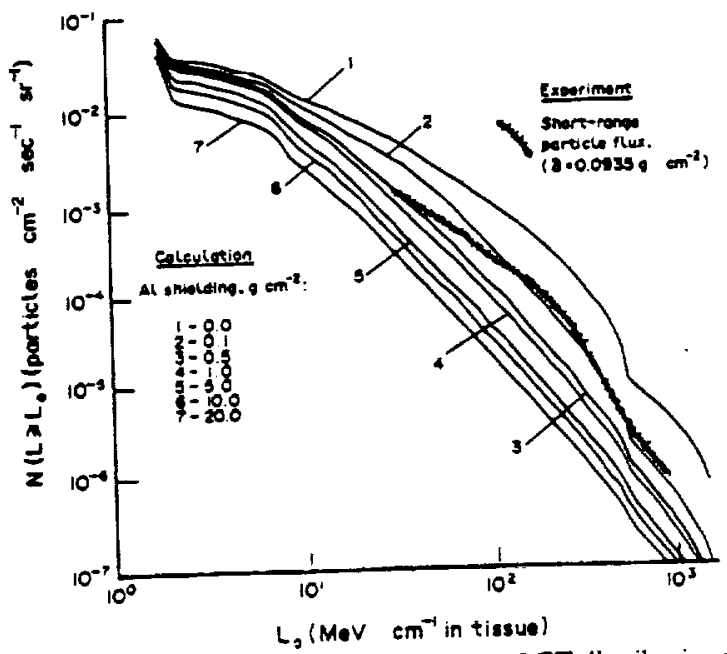

FIG. 3. Comparison of calculated integral LET distributions Fig. 3. Companson of calculated integral the experimental IET spectrum produced by short-range particles in the flight of Cosmos-2044.

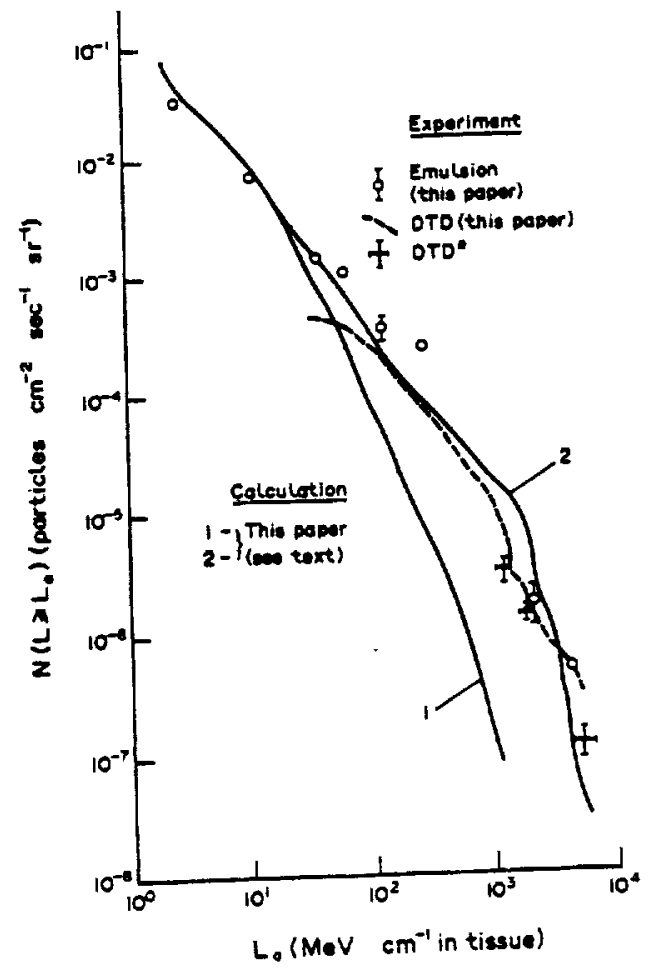

Fig 4. Comparison of calculated and experimental LET distributions in investigations on board Cosmos-2044 behind small shielding $\left(\delta=1.0-1.5 \mathrm{~g} \mathrm{~cm}{ }^{-2}\right)$-external assemblies. [०(DTD): Beaujean el al., 1990.]

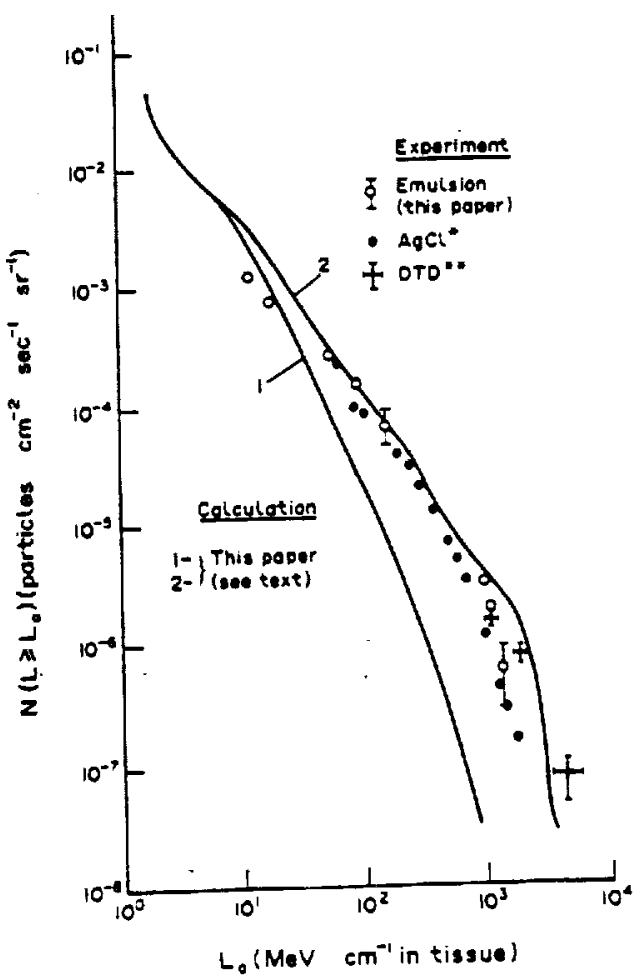

FIG 5. Comparison of calculated and experimental LET distributions in investigations on board Cosmos-2044 (bedistributions in investigations on board $\delta>10 \mathrm{~g} \mathrm{~cm}^{-2}$ )-internal assemblies. [ $(\mathrm{AgCl})$ : Baican et al., 1990; "“(DTD): Beaujean et al., 1990$. 


\section{E. DUDKIN et al.}

to the LET spectra are the short-range particles (under $L_{0}=200-300 \mathrm{MeV} \mathrm{cm} \mathrm{cm}^{-1}$ ), and with an increase of $L_{0}$ this role passes to the GCR particles. At $\delta>1.0 \mathrm{~g} \mathrm{~cm}^{-2}$, in practically the whole LET range of particles registered with CR-39, the bulk of the contribution belongs to the GCR particles.

Figures 3-5 demonstrate results of comparison of the experimental and calculated data. Comparison of LET distributions, calculated according to the U.S. code (without accounting for the contribution of the GCR particles with $Z>3$ ) and the experimental LET spectrum, produced by low-energy paricles with a residual path $<1200 \mu \mathrm{m}$ in CR-39 plastic (Fig. 3) with shielding $\delta \simeq 0.1 \mathrm{~g} \mathrm{~cm}^{-2}$, revealed a satisfactory agreement in the range of $L_{0}$ from 100 to $1000 \mathrm{MeV}$ $\mathrm{cm}^{-1}$. At $L_{0}<100 \mathrm{MeV} \mathrm{cm}{ }^{-1}$ the calculated curve surpasses the experimental one by approximately a factor of two, which may possibly be explained by the contribution to the total distribution from fast particles which have a residual path $>1200 \mu \mathrm{m}$ in the plastic detector.

Figures 4 and 5 show the comparison of experimental and calculated data with respect to LET distributions on the external surface of the satellite $(\delta$ $\simeq 1.0-1.5 \mathrm{~g} \mathrm{~cm}^{-2}$ ) (Fig. 4) and inside it $(\delta>10.0 \mathrm{~g}$ $\mathrm{cm}^{-2}$ ) (Fig. 5). The figures also include, for comparison, data obtained by other investigators during the flight of the satellite. Calculated curves in Figs 4 and 5 were constructed following the above-mentioned techniques (curve 1: the U.S. code, curve 2: the sum of curve 1 and the LET distribution contributed by GCR particles with $Z>3$, calculated by the Soviet program). Explanations of the experimental data are given in the corresponding figures. Results of experimental measurements made with different detectors (nuclear emulsions, plastic detectors, $\mathrm{AgCl}$ detectors) should be noted as to their satisfactory conformity with total calculated integral LET distributions. Differences in calculated and experimental data values at $L_{0} \geq 10^{3} \mathrm{MeV} \mathrm{cm}^{-1}$, apart from experimental errors, can also be explained by rather great statistical errors in calculations by the Monte Carlo method.

LET spectra from the present experiment were compared with results of our previous investigations of LET spectra (Akopova et al., 1990) for various inclinations of the orbit (i) from 60 to $83^{\circ}$. The Soviet satellite Cosmos-1757, as well as Cosmos-2044, had an inclination $i=82^{\circ}$. However, in the first case, the magnitude of the values of LET spectra flux was twoto three-fold higher compared with the present data. In our opinion, there are three factors which may be involved in this phenomenon. Firstly, Cosmos-1757 was in orbit in the period of deep SA-minimum when fluxes of the GCR particles in these orbits increase 1.5-2.0 times compared with the SA-maximum, when Cosmos-2044 was launched. Secondly, the shielding of detectors used for LET distribution measurements presented in Fig. $4\left(\delta=1.0-1.5 \mathrm{~g} \mathrm{~cm}^{-2}\right)$ was almost an order of magnitude greater than in the experiment on board Cosmos-1757 $\left(\delta=0.1-0.2 \mathrm{~g} \mathrm{~cm}^{-2}\right)$. This conclusion is also confirmed by measurements which were made in this experiment with plastic detectors behind various shieldings (Table 1). Indeed, the difference in fluxes behind $\delta=0.164 \mathrm{~g} \mathrm{~cm}^{-2}$ and $\delta=1.95 \mathrm{~g}$ $\mathrm{cm}^{-2}$ is almost equal to an order of magnitude. This difference is observed over the whole interval of LET which was registered by the plastic detectors. And, thirdly, in our work (Akopova et al., 1990) we took into account the fact that Cosmos-1757 was oriented and detectors were located on the external surface of the satellite in the spot where, to quote Akopova et al. (1989), the normalizing geometric factor, allowing for the spatial angle at whicb a CR particle penetrates a detector, was 4.1 against 6.28 in the fight of Cosmos2044. Each of these three factors affected an increase of the fluence of particles in the experiment on board Cosmos-1757 compared with Cosmos-2044.

The data contained in the integral LET spectra were used to estimate the radiation environment inside and outside the biological satellite. Values of absorbed and equivalent doses were calculated using

Table 2. Values of absorbed and equivalent doses obtained from experimental data and calculated values of LET spectra on board Cosmos-2044

\begin{tabular}{|c|c|c|c|c|c|}
\hline \multirow[b]{3}{*}{1} & \multirow[b]{2}{*}{ Data } & \multicolumn{2}{|c|}{$\begin{array}{c}\text { Outside } \\
\left(\delta=1.0-1.5 \mathrm{~g} \mathrm{~cm}^{-2}\right)\end{array}$} & \multicolumn{2}{|c|}{$\begin{array}{c}\text { Inside } \\
\left(\delta \geq 10 \mathrm{~g} \mathrm{~cm}^{2}\right)\end{array}$} \\
\hline & & $\underset{\text { mrad day }}{D}$ & $\begin{array}{c}H_{1} \\
\text { mrem day-1 }\end{array}$ & $\begin{array}{c}D \\
\text { mrad day-1 }\end{array}$ & $\begin{array}{c}H \\
\text { mrem day } \\
-1\end{array}$ \\
\hline & 2 & 3 & 4 & 5 & 6 \\
\hline 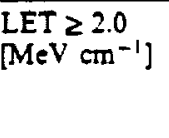 & $\begin{array}{l}\text { Calculation } \\
\text { Experiment } \\
\text { (NPE)* }\end{array}$ & $\begin{array}{c}9.30 \\
(\delta=1.0) \\
10.30 \\
(\delta=1.2)\end{array}$ & $\begin{array}{c}23.6 \\
(\delta=1.0) \\
27.5 \\
(\delta=1.2)\end{array}$ & $\begin{array}{c}4.40 \\
(\delta=20.0) \\
8.9 \\
(\delta=10.0)\end{array}$ & $\begin{array}{c}9.14 \\
(\delta=20.0) \\
14.5 \\
(\delta=10.0)\end{array}$ \\
\hline $\begin{array}{l}\text { LET } \geq 40.0 \\
{\left[\mathrm{MeV} \mathrm{cm}^{-1}\right]}\end{array}$ & $\begin{array}{l}\text { Calculation } \\
\text { Experiment } \\
\text { (CR-39) }\end{array}$ & $\begin{array}{c}1.38 \\
(\delta=1.0) \\
1.32 \\
(\delta=1.47) \\
1.53 \\
(\delta=1.49) \\
\end{array}$ & $\begin{array}{c}16.8 \\
(\delta=1.0) \\
12.8 \\
(\delta=1.47) \\
13.9 \\
(\delta=1.49)\end{array}$ & $\begin{array}{l}- \\
- \\
-\end{array}$ & $\begin{array}{l}- \\
-\end{array}$ \\
\hline
\end{tabular}

- NPE: nuclear photo-emulsion method. 


\section{EXPERIMENTAL AND CALCULATED LET IN COSMOS-2044}

Table 3. Calculated components of total absorbed dose (mrad day-1) in the orbit of Cosmos-2044

\begin{tabular}{|c|c|c|c|c|c|c|c|}
\hline \multirow[b]{2}{*}{ No. } & \multirow[b]{2}{*}{ Sources } & \multirow[b]{2}{*}{$h, \mathbf{k m}$} & \multicolumn{5}{|c|}{$\left(\delta, 8 \mathrm{~cm}^{-2}\right)$} \\
\hline & & & 1.0 & 1.5 & 2.0 & 10 & 20 \\
\hline \multirow[t]{2}{*}{1.} & \multirow{2}{*}{$\begin{array}{l}\text { Electrons } \\
\text { of } \mathrm{RBE}^{\star}\end{array}$} & 200 & 52.6 & 10.7 & 1.25 & 0.12 & - \\
\hline & & 300 & 72.0 & 20.0 & 1.73 & 0.17 & - \\
\hline \multirow[t]{2}{*}{2.} & \multirow{2}{*}{$\begin{array}{l}\text { Protons } \\
\text { of RBE* }\end{array}$} & 200 & 0.06 & 0.05 & 0.04 & - & - \\
\hline & & 300 & 3.71 & 3.20 & 2.94 & 1.11 & 0.52 \\
\hline \multirow[t]{2}{*}{3.} & \multirow[t]{2}{*}{ GCR } & 200 & 6.64 & 6.58 & 6.52 & 5.28 & 4.19 \\
\hline & & 300 & 6.71 & 6.65 & 6.58 & 5.34 & 4.29 \\
\hline \multirow[t]{2}{*}{4.} & \multirow[t]{2}{*}{$2+3$} & 200 & 6.70 & 6.63 & 6.62 & 5.30 & 4.20 \\
\hline & & 300 & 10.4 & 9.8 & 9.4 & 6.45 & 4.8 \\
\hline \multirow[t]{2}{*}{5.} & \multirow[t]{2}{*}{$1+4$} & 200 & 59.6 & 17.3 & 7.8 & 5.4 & 4.2 \\
\hline & & 300 & 82.4 & 30.0 & 11.2 & 6.6 & 4.8 \\
\hline
\end{tabular}

*RBE: radiation belts of Earth.

total flux curves (curves 3) in Figs 4 and 5 (Table 2, line 1). The table lists the values of doses obtained from the experimental data (nuclear emulsions) covering the whole interval of LET (Table 2, line 2), as compared with the plastic detector interval of $L_{0}$ $\geq 40 \mathrm{MeV} \mathrm{cm}^{-1}$ in tissue (Table 2, calculation: line 3; experiment: line 4).

The dose values in Table 2 do not include the contribution of electrons which, as it was shown in Akatov et al. (1990), at small shieldings can reach $70-90 \%$ of a total dose. In view of this, the dose values for maximal $S A$ would be: $D(\delta=1.0)=$ $69.3 \mathrm{mrad} d a y^{-1}$ and $H(\delta=1.0)=83.6 \mathrm{mrem} \mathrm{day}{ }^{-1}$ and $D(\delta=1.2)=27.8 \mathrm{mrad} \mathrm{day}^{-1}$ and $H(\delta=1.2)=$ 48.0 mrem day ${ }^{-1}$. Contribution of electrons at $\delta$ $>10 \mathrm{~g} \mathrm{~cm}^{-2}$ is negligibly small. The dose values calculated for positions inside the satellite are approximate due to the absence of information about mass distribution in the shielding which screened these detectors.

The rechniques described in Akatov et al. (1990), were used to calculate dose values for the orbit of Cosmos-2044. Results of these calculations, presented in Table 3, are in satisfactory agreement with the experimental data in Table 2.

\section{CONCLUSIONS}

(1) In orbits with a large angle of inclination, a strong dependence of the $\overline{C R}$ particle fluence on the shielding thickness is observed in a range from 0.1 to $2.0 \mathrm{~g} \mathrm{~cm}^{-2}$. This has been confirmed by previous investigations.

(2) For similar satellite orbits, the magnitude of total fluence is a function of the measurement period, i.e. on SA-phase.

(3) The LET spectra measured by different methods (nuclear emulsions, plastic detectors, $\mathrm{AgCl}$ detectors) are in satisfactory agreement within overlapping intervals of registration.

(4) Calculated estimations in an undisturbed magnetic field allow a satisfactory prediction of the results of experiments.

Future investigations should be aimed at quantifcation of total fuence of all particles including relativistic protons.

It is also necessary to give more detailed study to LET spectra with a sufficiently high experimental statistical accuracy in the area of very low $(<10 \mathrm{MeV}$ $\left.\mathrm{cm}^{-1}\right)$ and very high $\left(>5 \times 10^{3} \mathrm{MeV} \mathrm{cm} \mathrm{cm}^{-1}\right)$ LET values.

\section{REFERENCES}

Akatov Yu. A., Dudkin V. E., Kovalev E. E., Benton E. V., Frank A. L., Watts J. W. Jr and Parnell T. A. (1990) Depth distribution of absorbed dose on the external surface of Cosmos-1887 biosatellite. Nucl. Tracks Radiat. Meas. 17, 105-107.

Akopova A. B., Ambartsumian A. G., Dudkin V. E., Melkumian L. V., Potapov Yu. V. and Rshtuni Sh. B. (1989) Study of spectral characteristics of light auclei on Cosmos-1571. Space Irwest. XXVII (2), 318-321.

Akopova A. B., Magradze N. V., Dudkin V. E., Kovalev E. E., Potapov Yu. V., Benton E. V., Frank A. L., Benton E. R. Parnell T. A. and Watts J. W. Jr (1990) Linear Energy Transfer (LET) spectra of cosmic radiation in low Earth orbit. Nucl. Tracks Radiat. Meas. 17, 93-97.

Akopova A. B., Magradze N. V., Moiseenko A. A., Muradian S. H. and Ovanian K. M. (1983) Selective development of nuclear emulsions with thick layers. Preprint ErF1-661, 661-83, Yerevan.

Baican B., Schopper E., Wendnagel Th., Schott J. U. and Hailmann C. (1990) The life science experiment 'Seeds' on the Biocosmos satellite 9; Physical part. Abstracts of report on 15 th Int. Conf. Particle Tracks in Solids, Marburg, Germany, September 1990.

Beaujean R., Xopp J. and Enge W. (1990) Measurements of high-LET spectra on Biocosmos-9. Contr. 15th Int. Conf. Particle Tracks in Solids, Marburg, Germany, September 1990. IFKKI 90/4, pp. 5-8. 
